\title{
A adolescência em perspectiva: Um exame da variabilidade da passagem à idade adulta entre diferentes sociedades
}

\author{
Daniela Teixeira Dutra Viola ${ }^{1, *}$ \& Ângela Maria Resende Vorcaro ${ }^{1}$ \\ ${ }^{1}$ Universidade Federal de Minas Gerais, Belo Horizonte, MG, Brasil
}

\begin{abstract}
RESUMO - Este artigo propõe um exame da adolescência a partir de um debate entre a psicanálise e a etnologia. Considerando a variabilidade dessa passagem em diferentes sociedades, apresentamos alguns recortes extraídos de estudos etnológicos a fim de compreender o que garante essa operação em culturas não ocidentais. Com esse percurso, visamos contribuir para um melhor entendimento das coordenadas de Freud e de Lacan acerca da puberdade e seus desdobramentos no laço social, bem como vislumbrar novas leituras dos problemas da adolescência na contemporaneidade.

PALAVRAS-CHAVE: psicanálise, etnologia, adolescência, ritos de passagem
\end{abstract}

\section{Adolescence in perspective: an examination of the variability of passage into adulthood between different societies}

\begin{abstract}
This article proposes an examination of adolescence based on a debate between psychoanalysis and ethnology. Considering the variability of this passage in different societies, we present some insights taken from ethnological studies in order to understand what ensures this transition in non-Western cultures. Through this approach we expect to contribute to a better understanding of Freud's and Lacan's perspective about puberty and its consequences in the social bond, envisioning new readings on teenage problems nowadays.

KEYWORDS: psychoanalysis, ethnology, adolescence, rites of passage
\end{abstract}

A partir das coordenadas de Freud (1905/1996, 1909/1996, 1930/2010), compreendemos a adolescência como uma "tarefa" psíquica que precisa incluir, em uma mesma equação, a escolha do objeto sexual e a separação da família, com o consequente encaminhamento do jovem em direção à sociedade mais ampla. Trata-se de uma operação complexa, suscetível a diversas perturbações que podem impedir seu êxito (1905/1996). Por meio de algumas indicações de Lacan (1963/2005, 1974/2003), inferimos a hipótese de que essa operação subjetiva está relacionada à assimilação de um saber acerca do real da sexualidade - um saber sobre o impossível.

Vejamos os pontos da obra de Lacan (1963/2005, 1974/2003) que fundamentam nossa hipótese. Esse autor conecta a maturação pubertária com a possibilidade de assimilação dos conceitos ao afirmar que "o momento em que realmente começa o funcionamento do conceito [...] poderia ser situado [...] em função de um vínculo a ser estabelecido entre a maturação do objeto $a[\ldots]$ e a idade da puberdade." (1963/2005, p.282). Posteriormente, ao comentar a peça $O$ despertar da primavera, Lacan lhe atribui o mérito de demonstrar que na adolescência o encontro sexual não é satisfatório, e "se é mal sucedido, é para todo mundo" (1974/2003, p.557). Para ele, Wedekind, o dramaturgo da obra, antecipa Freud ao "se dar conta de que existe uma relação do sentido com o gozo" (1974/2003, p. 557). Lacan assinala que Freud demarca a sexualidade como aquilo que faz furo no real, e remete esse furo ao que irrompe na puberdade, quando o púbis "se exibe como objeto de uma levantada de véu" (1974/2003, p. 558). Em seguida, ele aponta a ligação disso com o que "se liga ao gozo do menino como proibido. Isto, certamente não para lhe proibir a relação dita sexual, mas para cristalizá-la na não-relação que ela vale no real." (1974/2003, p. 558). Ou seja, para Lacan a puberdade é o momento em que a impossibilidade da relação sexual é cristalizada para o sujeito. Assim, a tarefa da adolescência de apelo ao Outro, como alteridade constituída, lugar das trocas simbólicas (1964 [1960] /1998),

\footnotetext{
*E-mail: daniela.dutraviola@gmail.com
} 
inclui o encontro com o real do sexo e uma nova relação com os conceitos e com o saber.

Essas assertivas de Freud (1905/1996, 1909/1996, 1930/2010) e de Lacan (1963/2005, 1964 [1960] /1998, 1974/2003) viabilizam a distinção entre a puberdade e a adolescência. Enquanto a puberdade diz respeito ao real da maturação sexual que se manifesta no corpo e incide sobre a dimensão da imagem do sujeito, a adolescência concerne à forma como o sujeito vai se endereçar ao Outro e se reposicionar no laço social (Rassial, 1997), quando a condição de criança não puder mais lhe garantir essa posição. Como operação de reinscrição simbólica inextricável do discurso e do laço social, a adolescência varia consideravelmente de acordo com as diferentes formas de sociabilidade.

A partir dessas considerações, o presente artigo propõe uma interlocução entre a perspectiva psicanalítica da operação da adolescência - fase da vida que se apresenta como uma difícil travessia desde a modernidade dos tempos de Freud - e a perspectiva etnológica, que focaliza a diversidade dessa passagem conforme as diferentes etnias e culturas. Diferentemente da puberdade, que chega para as crianças de todas as realidades sociais, a chamada "crise" da adolescência não se estende a todas as sociedades, mas provém do discurso da Modernidade, que captura as particularidades da passagem à idade adulta nas sociedades ocidentais modernas. Além das mutações resultantes de um complexo processo sócio-histórico que conduz à noção de adolescência como um período crítico, é necessário considerar a grande variabilidade decorrente da diversidade cultural das sociedades não ocidentais (Deluz, 1999). Sendo assim, propomos uma reflexão sobre a passagem adolescente à luz de recortes extraídos de estudos etnológicos a fim de compreender o que garante essa operação nessas culturas. Com esse percurso, visamos contribuir para um melhor entendimento das coordenadas de Freud e de Lacan acerca da puberdade e seus desdobramentos no laço social, bem como vislumbrar novas leituras dos problemas da adolescência na contemporaneidade.

Ainda que não haja consenso entre os historiadores acerca do surgimento da ideia moderna de adolescência como fase da vida (Lesourd, 2004, p. 15), reconhecemos que ela aparece em um contexto sócio-histórico bastante próximo daquele que proporciona o surgimento da psicanálise. A sociedade moderna ocidental, na esteira dos avanços do Capitalismo e da industrialização, experimenta uma crise estrutural com mudanças expressivas nas relações sociais, públicas e privadas. Nessa crise, que se potencializa no século XIX, emerge a figura do adolescente moderno (Ariès, 1981), frequentemente associado à impetuosidade, à transgressão das normas da tradição até então vigentes e a uma sexualidade sem amarras. É possível considerar que essa figura do adolescente moderno é um dos efeitos do mal-estar na cultura (Freud, 1930/2010), assim como a própria psicanálise, que também nasce nesse momento histórico e nessa sociedade.

Portanto, a adolescência moderna já desponta como "crise", como elemento sintomático da civilização, como período associado aos comportamentos de risco, à violência, à errância e ao sofrimento. Por conseguinte, embora não constitua um conceito da psicanálise, a adolescência é um de seus grandes temas de interesse clínico e teórico desde as primeiras proposições de Freud sobre as jovens histéricas (Freud, 1905b/1996), até os dias de hoje, em que ocupa um lugar proeminente no discurso psicanalítico, às voltas com a gravidade de suas manifestações sintomáticas, que recaem sobre a clínica e sobre o campo social de forma contundente. Da modernidade à hipermodernidade (Lipovetsky, 2004), a adolescência passa por sensíveis transformações, uma vez que há importantes mutações no mundo contemporâneo em relação a elementos cruciais nessa passagem, tais como a família, os ideais, a transmissão de conhecimento e, sobretudo, a sexualidade. Em consequência dessas transformações, constatamos que os adolescentes de hoje tendem a vivenciar grandes dificuldades nesse encaminhamento à vida adulta, pois muitos não encontram referências que os auxiliem nesse caminho e ficam à deriva. Assim, os adolescentes estão cada vez mais vulneráveis à angústia e seus efeitos, como as passagens ao ato, as adições e os atos de marcar o corpo.

Se a passagem da criança ao adulto não é universalmente marcada por intempéries afetivas, mas sim varia enormemente de acordo com as diferentes realidades sociais, acreditamos que para examinar a adolescência que se apresenta à psicanálise é necessário delinear essa transição em outros contextos culturais. $\mathrm{O}$ que norteia a travessia da criança ao adulto em diferentes culturas? Como os jovens dessas culturas lidam com o saber sobre a sexualidade e com o excesso pulsional que acomete seus corpos? Com essas questões no horizonte, passamos a uma breve incursão na antropologia, a fim de extrair elementos que possam auxiliar em nossa aproximação dos desafios da operação adolescente na contemporaneidade ocidental.

\section{NATUREZA, SOCIEDADE E CULTURA}

No escrito A instância da letra no inconsciente ou a razão desde Freud, Lacan (1957/1998) demonstra a preexistência da linguagem, com sua estrutura, à entrada de cada sujeito em um momento de seu desenvolvimento mental. Neste que podemos considerar um dos pilares da hipótese estruturalista lacaniana, consta a proposição de que o sujeito, "se pode 
parecer servo da linguagem, o é ainda mais de um discurso em cujo movimento universal seu lugar já está inscrito em seu nascimento, nem que seja sob a forma de seu nome próprio" (Lacan, 1957/1998, p. 498). Ele prossegue com uma observação sobre a experiência da comunidade - que adquire sua dimensão essencial na tradição instaurada pelo discurso: "Essa tradição, muito antes que nela se inscreva o drama histórico, funda as estruturas elementares da cultura" (Lacan, 1957/1998, pp. 498-499). Estruturas que revelam uma ordenação inconsciente das trocas e permutações autorizadas pela linguagem. Esse trecho da obra escrita de Lacan é de grande relevância para nosso exame da fase de transição à idade adulta em culturas distintas da tradição judaico-cristã e da civilização ocidental - culturas chamadas, usualmente, de "primitivas", termo que adotaremos apenas provisoriamente. O que norteia a transição à vida adulta nessas culturas, que são extremamente diferentes umas das outras, mas que, comparando-se com nossa civilização, estão aparentemente próximas de um estado de "natureza"? Lacan problematiza a dicotomia natureza-cultura nos seguintes termos:
A dualidade etnográfica da natureza e da cultura está em vias de ser substituída por uma concepção ternária - natureza, sociedade, e cultura - da condição humana, na qual é bem possível que o último termo se reduziu à linguagem, ou seja, àquilo que distingue essencialmente a sociedade humana das sociedades naturais. (Lacan, 1957/1998, p.499).

Para Lacan (1957/1998), se há linguagem não se trata de "sociedade natural", mas sim de "sociedade humana". A introdução do laço social como termo essencial da "condição humana", implica um questionamento da dicotomia entre determinação cultural ou natural. Se vamos considerar a grande variabilidade dos fenômenos da adolescência entre uma cultura e outra, é preciso levar em conta a sociedade e a tradição, definida por Lacan (p. 499) como instrumento do discurso responsável por fundar as estruturas elementares da cultura. Tendo isso em vista, vamos examinar alguns recortes extraídos da antropologia que têm em comum um olhar sobre a passagem da infância à vida adulta.

\section{MARGARET MEAD E AS MENINAS DE SAMOA}

A antropóloga norte-americana Margaret Mead (1928) empreende um importante trabalho de campo acerca da transição da adolescência em sociedades ditas primitivas nas primeiras décadas do século XX. Com o objetivo de verificar o efeito da civilização sobre o desenvolvimento de um ser humano na idade da puberdade, ela passa nove meses em Samoa, uma ilha no sul do Oceano Pacífico habitada por povos nativos polinésios, observando a vida de dezenas de meninas adolescentes no cotidiano doméstico e na comunidade. Os resultados desse estudo e as conclusões de Mead são apresentados na obra Coming of age in Samoa (1928), livro pioneiro no campo das ciências sociais ao tratar da adolescência sob um enfoque multicultural.

Provocada por estudos das ciências sociais, da psicologia e da medicina que tomam a adolescência como um período de rebeldia, de conflitos subjetivos e de conturbadas transformações na personalidade, Mead (1928) parte da seguinte questão: as turbulências que atormentam nossos adolescentes se devem à natureza da adolescência em si mesma ou à civilização? (p. 11). Para respondê-la, ela investiga uma sociedade remota da sua, tanto cultural quanto geograficamente.

O estudo de Mead (1928) descreve em pormenores a vida na comunidade samoana, a divisão de trabalho, os costumes, os ritos, as peculiaridades da estrutura familiar e o dia-a-dia das adolescentes. Segundo a autora, a comunidade ignora as meninas e os meninos do nascimento aos 15 ou 16 anos de idade. As crianças e os adolescentes mais novos vivem quase imperceptivelmente à margem dos adultos. Até então, eles não têm um status social, exceto na participação de algumas danças típicas nas festas dos vilarejos. Não obstante, cerca de um ou dois anos após a puberdade, meninas e meninos são organizados em grupos específicos, grupos aos quais são atribuídos um nome, obrigações e privilégios na sociedade. Na verdade, os adultos também são distribuídos em grupos nomeados, o que confere à organização social samoana certa rigidez e grande previsibilidade na atribuição dos papéis na comunidade. Sendo assim, as meninas estudadas não têm escolha sobre o que vão fazer a partir da puberdade. Apenas aguardam o momento em que passam efetivamente a fazer parte da vida comunitária, por meio do pertencimento a determinado grupo.

Mead (1928) dedica uma parte extensa de seu trabalho à observação do comportamento sexual das adolescentes. Há um tabu na estrutura familiar que impede que irmãs e irmãos se aproximem. Durante a infância, as meninas tendem a estender esse tabu aos meninos em geral, mantendo algum distanciamento deles. Na época da puberdade, por volta dos 13 ou 14 anos, os meninos passam por um ritual de circuncisão, uma espécie de ratificação da diferença sexual. Nesse período, as meninas continuam a manter distância, o que se modifica somente em dois ou três anos, quando meninos e meninas passam a demonstrar mútuo interesse. De acordo com a autora, relações sexuais entre os adolescentes solteiros são aceitas socialmente. A homossexualidade é tolerada sem grandes ressalvas. Já o celibato não tem qualquer sentido para uma cultura em que a atividade sexual é concebida, segundo Mead (1928), como algo "natural” (p. 201).

É preciso examinar melhor a questão da "naturalidade" do sexo, tal como é compreendida por Mead (1928). Ela alega que a masturbação e a experimentação sexual na infância são tomadas sem grandes alardes, assim como 
os casos de homossexualidade entre as jovens que seu estudo acompanha. O tema do sexo faz parte do cotidiano das famílias, tal como a gravidez, o nascimento e a morte. A antropóloga sublinha que a educação em Samoa difere radicalmente da ocidental quanto ao tratamento desses temas. As crianças são desde cedo expostas a cenas em que esses fatos da vida aparecem - tais como o ato sexual, um parto ou a morte de uma pessoa próxima - e instruídas sobre elas em seus aspectos morfológicos. A ideia ocidental de privacidade não se aplica para essa sociedade da mesma maneira, mas isso por si só não explica a diferença radical entre a maneira como esses temas são tratados e transmitidos na cultura samoana e na ocidental. Segundo Mead (1928), o ponto principal para essa diferenciação é o que ela chama de uma "atitude mental" diante dessas questões: para os samoanos, nascimento, sexo e morte são "naturais", são "estruturas inevitáveis da existência". A autora acentua esse modo de conceber o sexo como um "fato físico da vida" em oposição à maneira como o tema da sexualidade em geral é extraído do universo das crianças ocidentais, através da frase "não é natural" (Mead, 1928, p. 220)'.

Conforme Mead (1928), nessa sociedade, a escolha sexual não constitui um dilema moral para os adolescentes. Ela estende essa ausência de dilema moral no plano da sexualidade para a ausência de dilemas e impasses na educação das crianças e adolescentes. $\mathrm{O}$ adolescente samoano não se defronta com a série de escolhas decisivas que são impostas aos adolescentes das sociedades ocidentais, tais como a escolha religiosa e profissional. Em uma sociedade tradicional caracterizada por poucas estratificações e variações, meninas e meninos não têm que lidar com dilemas complexos e decisivos, não são convocados a tomar posicionamentos que possam causar conflitos familiares ou rejeição social. Nesse sentido, a homogeneidade dessa sociedade garante a seus jovens uma transição à idade adulta mais previsível e programada, menos sujeita a conflitos e rupturas. Esse modelo de educação tende a atenuar as diferenças individuais e as discrepâncias, o que, para Mead, ajuda a minimizar a rivalidade entre os jovens e os possíveis conflitos daí decorrentes.

Trata-se de uma organização social em que os conflitos são minimizados por uma tendência à homogeneização. No plano familiar, isso também é verificado. Mead (1928) atribui o temperamento brando e pouco conflituoso dos membros de uma família samoana à maneira como as crianças são criadas. De acordo com ela, pais e filhos são muito mais distantes afetivamente que nas famílias ocidentais, o que, em seu entendimento, contribui para a ausência de estados emocionais indesejados. Além disso, há outros adultos que são também figuras de autoridade, como tios e tias em um mesmo ambiente doméstico, de maneira que os pais biológicos não ocupam um lugar de especial autoridade perante os filhos. Devido ao grande número de crianças em uma mesma família, a posição etária de cada uma, como a

1 Tradução nossa de expressões extraídas do original em inglês. do filho "mais velho", "do meio" ou "caçula", não exerce qualquer influência. A diferença sexual é instituída desde cedo por tabu, já que meninas e meninos são mantidos separados até a adolescência. Em vista disso, podemos deduzir que a estrutura familiar samoana é bastante diferente daquelas que predominam nas sociedades ocidentais quanto a importantes aspectos da trama edipiana.

Mead (1928) defende que todas essas particularidades explicitadas por seu trabalho de campo propiciam uma transição da adolescência mais suave, menos angustiada e conflitiva que aquela observada nas sociedades ocidentais, concluindo, assim, pelo estabelecimento de uma correlação fundamental entre a cultura e as circunstâncias da adolescência. Ela acrescenta que, diferentemente dos adolescentes das sociedades ocidentais - cuja puberdade inaugura necessariamente um período de estresse emocional, sofrimento e diversas formas de desajuste social -, as adolescentes samoanas de seu estudo demonstram que não são diferentes de suas irmãs de idade anterior ou posterior à puberdade, exceto em relação às mudanças físicas. Ou seja, a puberdade não é acompanhada da adolescência. A autora dá especial valor aos métodos educacionais samoanos, que minimizam as diferenças individuais, evitam a afloração de conflitos afetivos entre pais e filhos e, sobretudo, tratam das questões do sexo, da gravidez, do nascimento e da morte com "naturalidade", como "fatos físicos da vida" (Mead, 1928, p.220).

Ainda sobre esse caráter "natural" que alguns fatos da vida têm para os samoanos, parece-nos que Mead (1928) tenta designar uma forma de lidar com coisas que na sociedade moderna ocidental são encobertas, ao menos em parte, pela cultura - fatos da vida que não são apresentados de forma direta às crianças, em sua realidade "nua e crua". Lembrando que Mead alude à ausência de privacidade na vida doméstica samoana, percebe-se a diferença de tratamento desses fatos, cenas que na sociedade moderna são, em geral, abstraídas da percepção das crianças, a não ser em situações de desvelamento traumático, como no caso da visão da "cena primária" (Freud, 1918/1996). O que se desvela nessas cenas é algo inassimilável, de impossível apreensão pelos recursos simbólicos do sujeito.

Supomos que a assimilação desses fatos como "naturais" é a forma como os samoanos lidam com a impossibilidade de apreensão simbólica, como se assim tentassem burlar essa impossibilidade. Nessa perspectiva, sublinhamos que esses "fatos da vida" correspondem, conforme Lacan (1953/2005), ao registro do Real, são impossíveis de se inscrever no Simbólico. Logo, constatamos que a cultura samoana difere-se da cultura ocidental de forma mais contundente precisamente no ponto de tratamento do real do sexo e da morte, ao tomar esses elementos como fatos naturais e assim transmiti-los pela tradição no suceder das gerações. Deduzimos, assim, uma solução muito particular, prescrita pela tradição, para a transmissão e a assimilação do saber impossível sobre o real do sexo na passagem à vida adulta. 


\section{O RITO DE PASSAGEM: O TEMPO DA ADOLESCÊNCIA NAS SOCIEDADES TRADICIONAIS}

Lembremos as coordenadas de Lacan (1957/1998) a propósito da fundação das sociedades pela tradição, como instrumento do discurso. O antropólogo David Le Breton (2013) designa as sociedades "primitivas" como "sociedades tradicionais" (pp. 11-20). De acordo com ele, nessas sociedades os jovens não vivenciam a lacuna temporal característica da adolescência na cultura ocidental moderna - um tempo "entre-dois", em que o sujeito não tem mais os referenciais da infância nem conta ainda com as referências da vida adulta. No lugar dessa lacuna, as sociedades tradicionais instituem os ritos de passagem entre a infância e a maturidade social, quando o jovem chega a uma posição ativa e responsável na comunidade e tem acesso a saberes que são atribuídos a essa posição. No suceder das gerações, os saberes não perdem seu valor, e sim são transmitidos pelos antepassados e por uma cosmologia que abarca o conjunto das relações com o mundo. Portanto, nessas sociedades, a tradição é o instrumento que sustenta as referências para a passagem à idade adulta, entre as quais os ritos de passagem ocupam um lugar central.

Segundo a antropóloga Ariane Deluz (1999), os ritos de passagem permitem que os jovens assumam algo que os ultrapassa, o corpo social. Essa mudança de posição é sinalizada das mais diversas formas nas diferentes sociedades. Em muitas culturas, essa passagem é marcada por uma única cerimônia, que, quando terminada, com as redefinições induzidas pelo rito, passa-se de uma idade à outra. Nesses casos, a adolescência dura somente o instante dessa cerimônia. No final, a criança se torna um homem ou uma mulher, de acordo com as indicações culturais próprias a cada sexo. Em outras sociedades essa passagem pode durar alguns meses ou até anos, em modelos que vão desde uma sucessão de ritos e provações até longos períodos de uma errância de caráter iniciático. Apesar da grande variabilidade da passagem à idade adulta encontrada na diversidade das sociedades não ocidentais, percebe-se que esses modelos têm em comum uma temporalidade pautada pela tradição, de maneira que esses jovens não ficam à deriva em um tempo lacunar, mas sim atravessam de uma idade a outra no andamento definido pela cultura.

Nas sociedades modernas ou hipermodernas, não há rituais capazes de conduzir essa transição, que se dá de forma gradual. Tais sociedades são divididas em diversas classes sociais, nos mais variados grupos, provenientes de diferentes culturas, heterogeneidade que contribui para referências mais vagas e imprecisas, e para a longa permanência dos adolescentes em uma fase lacunar. Le Breton (2013) demonstra que os ritos de passagem das sociedades tradicionais operam o balizamento dessa transição, como marcadores, elementos da tradição que garantem aos jovens uma margem de manobra limitada. $\mathrm{Ou}$ seja, nessas sociedades, as orientações para existir e se localizar na comunidade são fornecidas com precisão pelo laço social.

Como indicam Deluz (1999) e Le Breton (2013), os dados culturais que definem o acesso à idade adulta variam substancialmente de uma sociedade para outra. Eles podem se apresentar como um único rito de passagem ou por uma série de etapas menores que formam um conjunto. Além da temporalidade regida pela tradição, os variados modelos de passagem têm em comum a função de reconhecimento e de instituição dos jovens em uma comunidade. Os ritos de iniciação têm o caráter de modificação radical do estatuto e do sentimento de identidade dos iniciados, que ascendem, assim, a um saber superior e a um novo status social, anteriormente cobiçado. Como eventos que assinalam uma morte simbólica, os ritos asseguram a transmissão social e o reconhecimento do sujeito pelo grupo, bem como demarcam a diferenciação entre homens e mulheres.

Em muitos casos, esses rituais são caracterizados por provações físicas dolorosas e por marcas no corpo, como circuncisões, perfurações, tatuagens, retirada de dentes e cabelos, amputações, etc. Le Breton (2013) ressalta a função da dor física e do traço marcado na pele, como agentes de metamorfose que precipitam a mutação social e provocam a mudança de identidade. A frequência e a incidência desses rituais dolorosos nas sociedades tradicionais, voltados para a transformação dos corpos, indicam o pertencimento do corpo do jovem ao corpo coletivo, à comunidade, como sendo uma particularidade importante dessas sociedades.

Le Breton (2013) enfatiza, ainda, que os ritos de passagem estão globalmente relacionados à revelação de um saber. Por meio deles, os antepassados transmitem inúmeros dados fundamentais para a comunidade, o que autoriza aos jovens o acesso às responsabilidades de mulher ou de homem, sob a égide dos ancestrais. Os mesmos valores são transferidos entre as sucessivas gerações. Deluz (1999) também explicita a importância da transmissão de saberes nos ritos de diversas sociedades. Geralmente, essa transmissão é atribuída a educadores de fora da família do jovem, o que mostra esse elemento quase universal da adolescência que é o afastamento do seio familiar e o deslocamento em direção à comunidade. Como exemplo de rito em que a transmissão dos saberes é destacada, ela menciona a iniciação entre os Senoufo, da Costa do Marfim:

Essa iniciação tem por objetivo ensinar às crianças todo o saber relativo à sociedade para que adquiram os valores dessa sociedade. Ela se faz numa idade relativamente avançada; em muitos grupos, foi reduzida a um ou dois ou três dias ou noites de iniciação num bosque sagrado, durante os quais a criança recebe um novo nome. Ela aprende por meios mnemotécnicos tudo o que deve saber dos mitos e dos valores da sociedade, uma língua nova. (Deluz, 1999, p.132) 
Com esse relato, observa-se que a apreensão do saber nessa forma de passagem é correlata à aprendizagem de uma nova língua, que se impregna na memória. Deluz (1999) nos informa, ainda, que aqueles que não passam por essa iniciação não são reconhecidos como membros do corpo social, pois permanecem crianças. Isso não ocorre somente entre os Senoufo. Em algumas sociedades, os jovens que não se mostram devidamente aptos para as provas físicas impostas durante os ritos chegam a ser banidos da sociedade, são excluídos do corpo social.

Também como exemplo de rito de passagem orientado pela transmissão de saberes, Deluz (1999) descreve a iniciação das moças Gouro, da Costa do Marfim, que entre 14 e 16 anos são enviadas a uma aldeia de mulheres e passam por um ritual de educação sexual:

Uma noite, depois de todas as mulheres terem avançado sobre a aldeia e dela expulsado os homens, as moças são levadas para a savana sagrada [...]; ali são submetidas a um rito de excisão, que é na verdade a subincisão do clitóris; não se corta o clitóris, faz-se uma incisão em sua base e o termo utilizado para essa operação é yerasa, isto é, lavar o rosto, o rosto sendo a metáfora do sexo. Isso quer dizer, na verdade, fazer sair o sexo, fazer sair o clitóris. Não se trata de clitoridectomia. Após essa operação relativamente dolorosa, as moças são trazidas para uma ou várias cabanas, ficam isoladas dos moradores durante vários dias, são tratadas, recebem curativos, os pais e os moradores da aldeia vêm lhes trazer presentes. A partir desse momento estão autorizadas a tocar nos objetos sagrados, [...] têm o direito se ir à savana; vão lá regularmente e é no interior da savana sagrada que se faz a instrução, que é, na verdade, uma educação sexual composta de jogos sexuais. (Deluz, 1999, p.135)

Nesse relato, verificamos que um saber sobre a sexualidade é transmitido pelo laço social e pelos referentes da tradição por meio de um rito que agrega a marcação dolorosa dos corpos e uma "educação sexual". Consequentemente, a inscrição sexual é operada pela cultura, as meninas Gouro são conduzidas a seu lugar na partilha entre os sexos pelas balizas do rito.

Nota-se, desse modo, a tradição como engrenagem dessas sociedades, em que se perde a dimensão do indivíduo, eclipsado pelas normas coletivas. Como consequência, a transição da infância à maturidade ocorre dentro de parâmetros estreitos. Os jovens estão fortemente ancorados por uma série de referenciais, que enlaçam seus corpos ao corpo social. Esses referentes estão condensados na estrutura dos ritos de passagem, que constituem uma simulação simbólica da morte seguida de um renascimento sob uma nova identidade - a passagem de um corpo infantil a um novo corpo. Para Le Breton (2013), o grupo garante a eficácia simbólica ${ }^{2}$ dessa operação, que faz

2 Conforme o conceito de Lévi-Strauss (1949/1996), que pressupõe, a partir de observações de ritos do xamanismo, a assimilação psíquica de algo impossível de ser significado, mas que é experimentado no corpo. com que os jovens não questionem o valor de suas vidas, pertencentes ao corpo coletivo. A assimilação simbólica consagra o pertencimento ao laço social e a determinado sexo, por meio de marcas corporais precisas. Nessa assimilação - ato operado pelo Outro - o rito imprime uma marca no corpo como insígnia do valor de uma vida para a coletividade.

Em alguns pontos de sua obra, Freud comenta sobre os ritos de passagem na puberdade em sociedades que chama de "primitivas". Na conferência introdutória sobre psicanálise "O simbolismo dos sonhos" (1916/2014), ao exemplificar as representações simbólicas do pênis em diversos contextos, ele alude a ritos da puberdade que representam a castração. O autor afirma que, em determinadas tribos da Austrália, há a prática da circuncisão "como rito de passagem à puberdade (para festejar a virilidade do jovem)" (p. 223), complementando que, em outras tribos próximas, o ato da circuncisão é substituído pela extração de um dente do menino púbere. Para ele, esse rito teria como função a punição da masturbação, por meio de um substituto da castração.

Posteriormente, na conferência introdutória "O desenvolvimento da libido e as organizações sexuais", Freud (1917/2014) volta a debater o assunto, desta vez em uma explanação didática acerca do complexo de Édipo. Como argumento para sua teoria edipiana, ele afirma que a primeira escolha objetal do ser humano é, em regra, incestuosa, daí a necessidade das mais severas proibições para impedir que essa propensão infantil persistente se realize. A propósito da interdição do incesto nessas sociedades e sua conexão com os ritos da puberdade, Freud recorre a um trabalho de Theodor Reik (conforme citado por Freud, 1917/2014), que cita sucintamente:

Nos povos primitivos ainda em existência nos dias de hoje, os povos selvagens, as proibições do incesto são ainda mais rigorosas que as nossas; em um trabalho brilhante, Theodor Reik mostrou há pouco tempo que o significado daqueles ritos da puberdade dos selvagens que representam um renascimento é a busca da eliminação da ligação incestuosa do menino com a mãe e de sua reconciliação com o pai. (Freud, 1917/2014, p. 445)

Desse modo, Freud (1917/2014) interpreta os ritos da puberdade das sociedades tradicionais a partir de uma chave de leitura que considera universal, ou seja, o complexo de Édipo. Ele sustenta que o incesto com a mãe e o parricídio são "os dois grandes crimes condenados pela a primeira instituição sociorreligiosa conhecida pelos seres humanos: o totemismo" (p. 446).

Sobre a universalidade do Édipo, na obra Os complexos familiares na formação do indivíduo, Lacan (1938/2003) assevera que Freud recebe o respaldo de um dado sociológico: 
Não apenas a proibição do incesto com a mãe tem um caráter universal, através das relações de parentesco infinitamente diversificadas e não raro paradoxais em que as culturas primitivas imprimem o tabu do incesto, como também, seja qual for o nível de consciência moral numa cultura, essa proibição é sempre expressamente formulada e sua transgressão é marcada por uma reprovação constante. (Lacan, 1938/2003, p. 54)

É preciso ler esse respaldo ao caráter universal do Édipo com a ressalva de que se trata de um argumento extraído de um contexto muito introdutório da obra de Lacan. Essa posição será modificada posteriormente, mesmo que não totalmente abandonada, em sua releitura da obra de Freud e na contínua construção e desconstrução, em espiral, de sua própria teorização. ${ }^{3}$ Guardada essa ressalva, voltemos às reflexões expostas nessa obra, que se reportam a um momento em que a matriz edipiana ainda parece prevalecer - embora seja nesse mesmo trabalho que o problema do declínio da imago paterna e seus efeitos no complexo edipiano comecem a ser debatidos. Escoltando o pensamento freudiano, Lacan (1938/2003) reitera que o complexo de Édipo não apenas marca o auge da sexualidade infantil, como também é o móbil da repressão que reduz suas imagens ao estado de latência até a puberdade. Na perspectiva de um Édipo universal, essa análise propicia a compreensão dos mecanismos dos ritos da puberdade como estreitamente atrelados à função simbólica edipiana - ritos a que Lacan faz alusão na seguinte passagem:

Tal gênese da repressão sexual não deixa de ter uma referência sociológica: ela se expressa nos ritos pelos quais os primitivos deixam patente que essa repressão prende-se às raízes do laço social - ritos de festa que, para liberar a sexualidade, desenham nela, por sua forma orgíaca, o momento de reintegração afetiva no Todo; ritos de circuncisão que, para sancionar a maturidade sexual, evidenciam que a pessoa só a alcança ao preço de uma mutilação corporal. (Lacan, 1938/2003, p. 59)

Na obra O mal-estar na civilização, Freud (1930) retoma o tema dos ritos da puberdade em um contexto que trata do vínculo e da divergência entre o amor e a civilização. $\mathrm{O}$ vínculo é inequívoco no curso da evolução humana, porém, o amor se opõe aos interesses da cultura, e esta o ameaça com restrições. (Freud, 1930/2010). Essa divergência, inevitável, tem origem no conflito entre a família e a comunidade mais

3 Acerca da abrangência etnológica do campo abarcado pelo discurso da psicanálise, em Radiofonia, Lacan (1970/2003) vai afirmar: “A partir de uma psicanálise, em si mesma, não se espere recensear os mitos que condicionaram um sujeito, pelo fato de ele haver crescido em Togo ou no Paraguai. Pois, como a psicanálise opera a partir do discurso que a condiciona, [...], não obteremos nenhum outro mito senão o que persiste em seu discurso: o Édipo freudiano.” (p. 409). ampla a que pertence o indivíduo. Ele lembra que um dos principais empenhos da civilização consiste em juntar os indivíduos em grandes unidades, as comunidades, mas a família não quer ceder o indivíduo, de maneira que quanto mais forte for o vínculo entre seus membros, maior a dificuldade em se afastar desse grupo e se dirigir ao círculo mais amplo da vida. Essa passagem entre um grupo e outro se dá geralmente na adolescência, o que leva Freud a afirmar que "a separação da família torna-se para todo jovem uma tarefa, na solução da qual a sociedade com frequência o ajuda por meio de ritos de puberdade e iniciação." (Freud, 1930/2010, pp. 66-67).

A leitura freudiana endossa a concepção de uma eficácia simbólica garantida pelos ritos de passagem da puberdade. Nos exemplos das sociedades tradicionais, as cerimônias de representação da castração como punição do incesto estabelecem balizas claras que sinalizam a travessia de um ponto a outro, configurando para o jovem seu reconhecimento no laço social como membro da tribo através de uma intervenção no corpo. Trata-se de uma forma chancelada de endereçamento ao Outro, que tem, como consequência, a abertura de acesso a novas dimensões do saber.

Freud (1909/1996) não restringe sua análise dos ritos da puberdade às culturas ditas "primitivas", mas sim a estende ao que ele chama de "tarefa" do jovem, a saber, a separação da família com o decorrente endereçamento ao Outro, à sociedade - no sentido que Lacan (1957/1998) lhe atribui ao incluí-la como terceiro termo no eixo natureza-cultura. Nessa perspectiva, os ritos de passagem têm a função de referenciar o jovem nessa tarefa, de tomá-lo pela mão nesse percurso, como indica a ideia de uma "ajuda" por parte da sociedade. Ainda que essa função dos ritos possa ser estendida à sociedade moderna da época de Freud, é preciso frisar que sua eficácia simbólica já não é mais a mesma das sociedades tradicionais. Com a passagem para as sociedades modernas, isto é, com o enfraquecimento paulatino e crescente da tradição como elemento fundamental da sociedade, perde-se, gradualmente, o valor simbólico desses rituais, que assumem cada vez mais um caráter imaginário, pois o que prevalece nesses novos ritos é a reprodução da imagem de uma adolescência estereotipada e transitória, em convenções sociais que oscilam conforme os modismos. Esses ritos não conseguem intervir como delimitadores do gozo que irrompe na puberdade, pois não há intervenção nos corpos proveniente do laço social. Nos tempos do "cada um por si", o adolescente tem que lidar com o gozo à sua maneira, com um corpo que é só seu, ainda que lhe seja estranho. Os ritos só obtêm uma eficácia simbólica nas sociedades tradicionais porque os corpos não pertencem aos indivíduos, mas sim à coletividade. 


\section{A PERSPECTIVA DO CORPO COLETIVO}

Com os antropólogos Margaret Mead (1928), Ariane Deluz (1999) e David Le Breton (2013), aprendemos que a transição da adolescência nas sociedades tradicionais se dá de maneira muito distinta da adolescência moderna, tal como é debatida pela psicanálise. Nessas sociedades, não há propriamente adolescência, visto que a mudança do estatuto de criança ao de adulto se dá de forma ritualizada, é conduzida pelas balizas da tradição. Nesses casos em que a tradição engendra a mudança de idade, em que o rito de passagem substitui a adolescência, essa transição se mostra, aparentemente, mais próxima da "natureza", o que é realçado com frequência no estudo de Mead.

É preciso problematizar essa suposta proximidade da natureza, que está associada ao apagamento do indivíduo. Nessas sociedades, o corpo do jovem pertence a um corpo coletivo. As diferenças individuais são minimizadas. A singularidade quase não tem lugar. Essas sociedades estão aparentemente mais próximas de um estado de natureza porque têm como princípio uma concepção cíclica da vida, espelhada nos ciclos naturais, em que tudo deve voltar sempre ao mesmo lugar e em que cada indivíduo é uma peça entre outras para o perfeito funcionamento do ciclo. A adolescência, porém, aponta para o futuro, para o novo e para o desconhecido, logo é incompatível com a previsibilidade de uma concepção cíclica da vida. Nessas sociedades, a tradição garante que esse ciclo se feche a cada geração, atuando como elemento mediador entre a cultura e a natureza, como balizador do real, daquilo que escapa à cultura, mas que nem por isso se confunde com a natureza. A tradição estabelece parâmetros que realizam uma espécie de "naturalização" artificial do real, como verificamos na maneira como essas sociedades lidam com os temas do sexo e da morte. Por conseguinte, a determinação cultural da adolescência é depreendida por sua ausência nessas sociedades, em que é substituída por mecanismos simbólicos responsáveis por uma espécie de simulação da ordenação da natureza. Determinação cultural e naturalização simulada estão, portanto, entrelaçadas, o que corrobora o questionamento de Lacan (1957/1998) sobre a ineficácia da dualidade natureza-cultura como um par de opostos que define a condição humana.

Para encerrar nossa breve incursão antropológica, interpolamos nesse debate uma contribuição da antropologia amazônica contemporânea com o intuito de amplificar e problematizar a discussão sobre a oposição natureza-cultura, bem como enfatizar a grande variabilidade da passagem da criança ao adulto em diferentes sociedades. Evocamos a oposição natureza-cultura à luz do perspectivismo ameríndio - conceito central, conforme o antropólogo Eduardo Viveiros de Castro (2007), que caracteriza as cosmologias desses povos e se refere ao modo como as diferentes espécies de sujeitos (humanos e não-humanos) que povoam o cosmos percebem a si mesmas e às demais espécies. Viveiros de Castro afirma:

As relações com a natureza não são nunca, tratando-se de sociedades humanas, relações naturais, mas relações sociais. Não só elas se travam a partir de formas sociopolíticas determinadas, como pressupõem dispositivos simbólicos específicos, isto é, instrumentos conceituais de "sintonia" com o real [ou de "apropriação da natureza", conforme o gosto ideológico de cada um], instrumentos que têm por característica distintiva o serem culturalmente especificados, isto é, relativamente arbitrários, e não determinados univocamente por parâmetros extraconceituais. [...]. Se as ideologias modernas tendem a ver as sociedades indígenas, para bem ou para mal, como parte da natureza - mas isto é verdade para toda sociedade humana - , podemos então dizer que as culturas indígenas tendem a ver a natureza como ela mesma parte da sociedade, ou antes, como mergulhada, tanto quanto o mundo humano, em um meio universalmente social - o que não é menos universalmente verdadeiro. (Viveiros de Castro, 2007, p.7).

Pois bem, em consonância com a teoria lacaniana do laço social, em se tratando de sociedades humanas, só há relações sociais, nunca relações naturais. Ainda nessa trilha, para Viveiros de Castro (2007), o perspectivismo não pode ser confundido com um relativismo cultural, ou um "multiculturalismo", que supõe uma diversidade de representações subjetivas e parciais a incidir sobre uma natureza externa, única e total. Ao invés disso, trata-se de um "multinaturalismo", termo que ele propõe para demarcar como os ameríndios concebem uma unidade representativa aplicada indiferentemente sobre uma diversidade real. Isto é, "uma só 'cultura', múltiplas 'naturezas'; epistemologia constante, ontologia variável - o perspectivismo é um multinaturalismo, pois uma perspectiva não é uma representação [...] porque as representações são propriedades do espírito, mas o ponto de vista está no corpo" (Viveiros de Castro, 2007, pp. 11-12).

Viveiros de Castro (2007) clarifica que a tradição ocidental concebe uma "natureza humana", caracterizada pela separação problemática entre o corpo e o "espírito", cujo nome moderno é a cultura. (p. 12). Nesse sentido, há uma continuidade física e uma descontinuidade metafísica entre os humanos e os animais, estes da ordem da natureza. O "espírito", ou a cultura, é o grande diferencial do que concerne ao humano, é o que garante sua particularidade em meio às demais espécies. Já o corpo é o que integra o ser humano à natureza, o que o universaliza. Em contrapartida, os ameríndios concebem uma continuidade metafísica e uma descontinuidade física entre os seres do cosmos. Essa concepção traz implicações cruciais para a forma como se dá a transição à idade adulta nessas 
sociedades. Enquanto nas sociedades modernas a noção de adolescência está radicalmente ligada à subjetividade e ao "espírito", nessas comunidades tal noção é inconcebível e a transição se dá de forma ritualizada, pautada por uma cosmologia que prevê que "os corpos são o modo pelo qual a alteridade é apreendida como tal" (Viveiros de Castro, 2007, p. 12).

Viveiros de Castro (1979) esclarece que, para os ameríndios, o corpo é construído, fabricado, assim como o parentesco. Já a alma não é feita, mas dada, seja na concepção, seja capturada do exterior, até mesmo tomada de outro indivíduo. Como exemplo, para os Yawalapíti, tribo pesquisada por esse antropólogo, a origem da humanidade provém do processo de fabricação dos corpos humanos a partir da fumaça de tabaco que sopra sobre toras em um local de reclusão. Esse mito fundamental é reproduzido em cada ocasião de rito da puberdade, no caso dessa tribo um rito de reclusão. Acerca desse rito, Viveiros de Castro (1979) observa:
Toda reclusão é sempre concebida, para os Yawalapíti, como uma mudança substantiva do corpo. Fica-se recluso, dizem, para "trocar o corpo", "mudar o corpo". Não apenas para isso, é certo: para formar, também, ou reformar, a personalidade ideal-adulta, sobretudo no caso da reclusão pubertária, a mais importante. [...] Aqueles que não seguiram as regras alimentares e sexuais da reclusão tornam-se ipuñoñori-malú, "gente imprestável", e são candidatos ideais a acusações de feitiçaria, além de sofrerem "defeitos" físicos típicos dos feiticeiros: "barriga inchada" [por acúmulo de sangue, resultado de incontinência alimentar específica, ou sexual], pequena estatura [incontinência sexual do adolescente recluso]. (Viveiros de Castro, 1979, p. 44)

Percebe-se, com esse exemplo, a particularidade da transição à idade adulta nessas sociedades, mudança que é operada por elementos da tradição muito específicos. No caso dos Yawalapíti, é especialmente notável a conexão estabelecida entre essa passagem e a origem da humanidade, sinalizando o valor da puberdade para um povo que lida com a dualidade natureza-cultura a partir do referencial do corpo.

\section{CONSIDERAÇÕES FINAIS:A ADOLESCÊNCIA NAS SOCIEDADES HIPERMODERNAS}

Compreendemos, enfim, que a adolescência, em seu sentido moderno, não tem lugar nessas sociedades tradicionais, assim como não é concebível em outras épocas, anteriores à modernidade, em que a tradição também opera a transição à idade adulta e a transmissão de saberes. Nas sociedades modernas, marcadas pelo enfraquecimento da tradição e pela diluição dos referenciais, não há como balizar o que se passa entre um ponto e outro desse intervalo de tempo, em que tudo pode se modificar. Diferentemente das sociedades tradicionais em que o corpo do jovem pertence ao corpo coletivo, e é entregue à comunidade no momento do rito para ser manipulado e transformado - como podemos vislumbrar com o exemplo dos Yawalapíti - nas sociedades modernas o corpo do adolescente está à deriva, desgarrado de referências e vulnerável a um gozo que não é suficientemente contido. Esse corpo é constantemente testado em seus limites, nas condutas de risco, nas adições e na exploração ilimitada da sexualidade.

Isso explica a forte tendência dos adolescentes da contemporaneidade em procurar marcações no corpo, que buscam conter o gozo com traços dolorosos, tais como tatuagens, piercings, incisões e escarificações, em tentativas, muitas vezes radicais, de imprimir na pele um marco delimitador, um ponto de basta. Todavia, essas marcas não provêm da tradição, não garantem a eficácia simbólica tal como nos rituais de passagem tradicionais, de modo que não são eficientes em estancar o gozo que toma esses corpos. Trata-se de marcas geralmente precárias e provisórias, pois provêm de atos que não passam pelo Outro, mas reproduzem, em iteração, sintomas coletivos proliferados pelo grande espelho da web. Enquanto o jovem Yawalapíti sai de sua reclusão ritualística definitivamente marcado pelo Outro, os jovens de nosso tempo buscam incessantemente essa marcação, dificilmente a alcançando.

Retomemos a hipótese de uma operação da adolescência que articula a reinscrição simbólica do sujeito com o confronto com o real do sexo, de maneira que se inaugura uma nova forma de se relacionar com o saber. Podemos afirmar que essa operação é resolvida, nas sociedades tradicionais, pelos mecanismos simbólicos de transmissão e assimilação do saber, que constituem os ritos de passagem. Trata-se de uma forma de burlar a impossibilidade do saber sobre o sexo, de dar um tratamento a esse impossível pela via de uma suposta "naturalização", pelo apagamento da individualidade, com a concepção de pertencimento dos corpos a um coletivo.

Nas sociedades ocidentais modernas e hipermodernas essa operação encontra dificuldades, o que se apresenta como "crise" da adolescência. Desde a modernidade, é tangível a conexão entre a adolescência e a dimensão sintomática da civilização, uma vez que o adolescente traz à cena social de maneira transgressora a incidência do real do sexo, como elemento do gozo que escapa aos mecanismos de controle da sociedade. Ao mesmo tempo em que a adolescência se torna alvo da sociedade disciplinar (Foucault, 1975/1999), ela ascende ao status de "idade favorita" no discurso do século XX (Ariès, 1981), graças a essa posição duplamente subversiva encarnada pela figura do adolescente: como aquele que desvela, mesmo sem autorização da sociedade, o despertar da sexualidade, mas também como aquele a quem pertence o futuro, o imponderável, o devir. 
Essas circunstâncias sociais que afetam sensivelmente a passagem da adolescência nos tempos modernos de Freud se agudizam no mundo contemporâneo. Segundo o sociólogo Gilles Lipovetsky (2004), a hipermodernidade é a modernidade elevada à potência superlativa, que ao invés de ser superada, por uma era pós, é, na verdade, hiperbolizada. O que se assiste é sua concretização no liberalismo globalizado, com a mercantilização quase generalizada dos modos de vida e com a individualização galopante. (Lipovetsky, 2004, p. 53).

A juventude ocupa um lugar central nestes tempos da "pulsão neofílica", em que o sujeito sonha em se assemelhar a uma "fênix emocional", recusando o tempo exaurido e buscando sempre combater, pela via da "fúria consumista", o envelhecimento das sensações. (Lipovetsky, 2004, pp. 7980). É a versão superlativa e hipertrofiada da adolescência como "idade favorita".

Predomina, entre os mais jovens, um sentimento de vulnerabilidade, de insegurança profissional e material. (Lipovetsky, 2004). Assim, a hipermodernidade é um tempo de angústia para os adolescentes diante das incertezas do futuro. Como observa Lipovetsky (2004), "o ambiente da civilização do efêmero fez mudar o tom emocional" ( $p$. 63). Trata-se de uma mudança de tonalidade, e não do que sugere a "mitologia da ruptura radical" (p. 57), que supõe uma mudança drástica de paradigma com a superação da modernidade, perspectiva que deve ser nuançada. Diferentemente do clima otimista e frívolo de algumas décadas atrás, o que constatamos agora é "uma exigência generalizada de proteção". (p. 64).

Dessa forma, em uma época caracterizada pela desregulação, pelo enfraquecimento dos referentes da tradição, e pela efemeridade, mobilidade e inconstância do laço social, a transição da criança ao adulto não se dá mais como antes, já que as balizas de outrora não estão mais disponíveis, ao menos não em abundância. Ao se separar da referência familiar - também consideravelmente transformada nas últimas décadas - e se endereçar ao laço social, o jovem não conta com sinalizadores precisos. $\mathrm{O}$ Outro não dá as coordenadas, é cada vez mais inconsistente. As figuras de autoridade e os ideais estão mais desgastados e provisórios, o que se reflete na relação com o saber, que passa cada vez menos por essas figuras. Prevalecem modalidades virtuais de acesso ao conhecimento, de forma desordenada e desregulada, em meio a um universo virtual em que a informação não tem limites. Esse excesso de informação afeta a relação do jovem com o saber na passagem adolescente, visto que os marcadores simbólicos, que poderiam auxiliar no confronto, sempre traumático, com o saber impossível sobre o sexo, estão cada vez mais dispersos. Portanto, diferentemente dos jovens das sociedades tradicionais que acolhem o saber transmitido pelos ancestrais nos ritos de passagem, os adolescentes hipermodernos estão à deriva em um oceano virtual de informação e conhecimento, o que não garante a transmissão de saber.
Além do acesso ilimitado e desordenado à informação, os adolescentes estão suscetíveis ao imperativo do gozo e do hiperconsumo. Tendem a ocupar um lugar central no discurso, um ponto de sintoma, precisamente por sua posição de resto, análoga ao objeto $a$ que está no zênite (Lacan, 1970/2003). Portanto, o adolescente é, ao mesmo tempo, objeto-agalma, como aquele que representa todas as aspirações da sociedade atual, a "fênix emocional", e objetofalta, a quem se destina uma profusão de objetos descartáveis produzidos pelo mercado, incapazes de tamponar o vazio proveniente da não inscrição desses sujeitos no Outro. (Kehl, 2004). Essa posição de objeto difere radicalmente daquela ocupada pelos jovens nas culturas tradicionais, em que estão inseridos em um corpo social.

No artigo "A juventude como sintoma da cultura", Maria Rita Kehl (2004) esclarece que o adolescente é alvo do mercado capitalista, pois "essa longa crise que alia o tédio, a insatisfação sexual sob alta pressão hormonal, a dependência em relação à família e a falta de funções no espaço público, acabou por produzir o que as pesquisas de marketing definem como uma nova fatia de mercado" (s.p., parágrafo 4). Essa captura pelo mercado não ocorre apenas nas classes econômicas privilegiadas, mas sim em todas as esferas sociais. O consumo é um dos meios de que o adolescente contemporâneo dispõe para tentar conter aquilo que excede seu corpo, o real do sexo que irrompe na puberdade. A autora acrescenta:

Em nossas sociedades laicas, em que faltam ritos de passagem para sinalizar o ingresso na vida adulta, os objetos de consumo e os espaços próprios para frequentação adolescente - a lanchonete, o baile funk, a boate, os mega-shows de rua substituem os ritos característicos das culturas pré-modernas. Os jovens também inventam seus próprios ritos. (Kehl, 2004, s.p., parágrafo 11)

Em vista dessas constatações, corre-se o risco de se abordar a adolescência atual por um ponto de vista pessimista, sombrio, às vezes até mesmo catastrófico, em interpretações que deduzem a impossibilidade do sujeito se reinscrever no Outro nesse momento da vida em meio ao declínio dos ideais. Mesmo em face da contundência das mutações no real e no laço social dos tempos contemporâneos, concordamos com Lipovetsky (2004) quanto à necessidade de nuances nos diagnósticos da época e de apostas no sujeito, sobretudo no sujeito adolescente, que costuma ser dotado de especial habilidade para invenções. Em consonância com o que sustenta Kehl (2004), consideramos que os adolescentes de hoje podem inventar suas próprias soluções. E a psicanálise exerce um papel fundamental na sociedade ao constituir um dispositivo e um discurso que recusam a mercantilização do sofrimento dos adolescentes e dão lugar ao saber e às invenções desses sujeitos. 


\section{REFERÊNCIAS}

Ariès, P. (1981). História social da criança e da família (D. Flaksman, Trad., pp. 130-139). Rio de Janeiro: LCT.

Deluz, A. (1999). Comunicação de Ariane Deluz. In A. Deluz, B. Gibello, J. Hébrard, O. Mannoni, C. Audry, \& S. Baruck (Org.), A crise de adolescência (P. Abreu, Trad.). Rio de Janeiro: Companhia de Freud.

Foucault, M. (1999). Vigiar e punir. (R. Ramalhete, Trad.) Petrópolis, Vozes. (Trabalho original publicado em 1975)

Freud, S. (1996). Três ensaios sobre a teoria da personalidade. In Um caso de histeria; Três ensaios sobre sexualidade e outros trabalhos (Edição Standard, Vol. 7). Rio de Janeiro: Imago. (Trabalho original publicado em 1905)

Freud, S. (1996). Fragmento da análise de um caso de histeria. In Um caso de histeria, Três ensaios sobre a teoria da sexualidade e outros trabalhos. (J. Salomão, trad., vol. 7). Rio de Janeiro: Imago. pp. 15-116. (Trabalho original publicado em 1905b)

Freud, S. (1996). Romances familiares. In "Gradiva" de Jensen e outros trabalhos (Edição Standard, Vol. 9). Rio de Janeiro: Imago. (Trabalho original publicado em 1909)

Freud, S. (2014). Conferência introdutória sobre psicanálise 10: O simbolismo dos sonhos. In Conferências introdutórias sobre psicanálise. Segunda parte (Vol. 13, P.S. Souza, Trad.). São Paulo: Companhia das Letras. (Trabalho original publicado em 1916)

Freud, S. (2014). Conferência introdutória sobre psicanálise 21: O desenvolvimento da libido e as organizações sexuais. In Conferências introdutórias sobre psicanálise. Terceira parte (Vol. 13, P.S. Souza, Trad.). São Paulo: Companhia das Letras. (Trabalho original publicado em 1917)

Freud, S. (1996). História de uma neurose infantil. In Uma neurose infantil e outros trabalhos (Edição Standard, Vol. 17). Rio de Janeiro: Imago. (Trabalho original publicado em 1918)

Freud, S. (2010). O mal-estar na civilização. In $O$ mal-estar na civilização, Novas conferências introdutórias à psicanálise e outros textos (Vol. 18, P.S. Souza, Trad.). São Paulo: Companhia das Letras. (Trabalho original publicado em 1930)

Kehl, M. R. (2004). A juventude como sintoma da cultura. Recuperado de http://outrascrateras.blogspot.com.br/2010/08/ juventude-como-sintoma-da-cultura.html?m=1

Lacan, J. (2003). Os complexos familiares na formação do indivíduo. In Outros escritos (V. Ribeiro, Trad.). Rio de Janeiro: Jorge Zahar Editor. (Trabalho original publicado em 1938)

Lacan, J. (2005). O simbólico, o imaginário e o real. In Nomesdo-Pai (A. Telles, Trad.). Rio de Janeiro : Zahar. (Trabalho original apresentado em 1953)

Lacan, J. (1998). A instância da letra ou a razão desde Freud. In Escritos (V. Ribeiro, Trad.). Rio de Janeiro : Jorge Zahar Editor. (Trabalho original apresentado em 1957)
Lacan, J. (1998). Posição do inconsciente. In Escritos (V. Ribeiro Trad.). Rio de Janeiro: Jorge Zahar Editor. (Trabalho original apresentado em 1960 e retomado em 1964)

Lacan, J. (2005). Seminário livro 10 - A angústia (V. Ribeiro, Trad.). Rio de Janeiro: Jorge Zahar Editor. (Trabalho original proferido em 1963)

Lacan, J. (2003). Radiofonia. In Outros escritos (V. Ribeiro, Trad.). Rio de Janeiro: Jorge Zahar Editor. (Trabalho original apresentado em 1970)

Lacan, J. (2003). Prefácio a: O despertar da primavera. In Outros escritos (V. Ribeiro, Trad.). Rio de Janeiro: Jorge Zahar Editor. (Trabalho original publicado em 1974)

Le Breton, D. (2013).Une brève histoire de l'adolescence. Paris : Éditions J.-C. Béhar.

Lesourd, S. (2004). A construção adolescente no laço social (L. Magalhães Trad.). Petrópolis: Editora Vozes.

Lipovetsky, G., \& Charles, S. (2004). Os tempos hipermodernos (M. Vilela, Trad.). São Paulo: Barcarolla.

Mead, M. (1928). Coming of age in Samoa. Nova York: W. Morrow \& Company.

Rassial, J-J. (1997). A passagem adolescente: Da família ao laço social. Porto Alegre: Artes e Ofícios.

Reik, T. (1946). The puberty rites of savages. In Ritual: Psychoanalytic studies (pp. 128-163). Nova York: Farrar, Straus and Company. (Trabalho original de 1915-1916)

Viveiros de Castro, E. (1979). A fabricação do corpo na sociedade xinguana. Boletim do Museu Nacional, 32, 2-19. Recuperado de http://www.etnolinguistica.org/pessoa:castro.

Viveiros de Castro, E. (2007). A natureza em pessoa: Sobre outras práticas de conhecimento. Recuperado de http://www. socioambiental.org/banco_imagens/pdfs/visesdoriobabel.pdf.
Recebido: $25 / 06 / 15$

Revisões 13/10/2015

Aceito: 09/05/16 